\title{
Survival of dental implants placed in autogenous bone grafts and bone flaps in head and neck oncology patients: a systematic review
}

\author{
Dominic P. Laverty ${ }^{1 *}$, Robert Kelly ${ }^{2}$ and Owen Addison ${ }^{2,3}$
}

\begin{abstract}
Using implants to retain prostheses as part of the oral rehabilitation of head and neck cancer patients is an increasingly common treatment modality, particularly in transported bone which is used to reconstruct defects following oncological surgical resection. The aim of this systematic review is to evaluate the survival of dental implants placed into autogenous bone grafts and flaps, in head and neck cancer patients. MEDLINE, EMBASE, CENTRAL and Science Direct databases were searched (1980-August 2017) for studies evaluating intra-oral implant placement into autogenous bone grafts and flaps in H\&N cancer patients. Twenty articles were included reporting on 1905 implants placed into autogenous bone in head and neck cancer patients. Implant survival varied from 54 to $100 \%$ within the studies with 11 studies reporting implant survival of over $90 \%$. In conclusion, intra-oral implant survival in autogenous bone grafts in head and neck oncology patients is promising, however inconsistencies in data reporting and in outcome definitions precludes formal meta-analysis.
\end{abstract}

Keywords: Dental implants, Autogenous bone graft, Head and neck oncology, Implant survival

\section{Review Introduction \\ Rationale}

The use of implants to retain prostheses as part of oral and dental rehabilitation of head and neck $(\mathrm{H} \& \mathrm{~N})$ cancer patients is becoming an increasingly common treatment approach [1-3]. A number of benefits advocating implant anchorage over conventionally secured prostheses have been proposed [4] but importantly include a significant improvement in the reported quality of life (QoL) of patients [5].

Patients with H\&N cancer often undergo ablative surgery with or without surgical reconstruction, radiotherapy and chemotherapy $[4,6]$. Both surgical and non-surgical interventions can lead to significant disability, including facial deformity, loss of hard and soft tissue, impaired speech, swallowing and mastication [7]. Oral and dental

\footnotetext{
* Correspondence: dominiclaverty560@hotmail.co.uk

${ }^{1}$ Birmingham Community Healthcare NHS Foundation Trust, Birmingham B5 7EG, UK

Full list of author information is available at the end of the article
}

rehabilitation has conventionally required the use of removable prostheses to obturate defects, to replace missing tissue structures and to restore function and aesthetics. In this patient group, removable prostheses are often poorly tolerated, are difficult for the patient to maintain and frequently fail to fully achieve the intended functional improvement. The use of dental implants has been proposed to enable secure anchorage for prostheses, reduced loading on vulnerable tissues and provide a better functional and cosmetic solution [8].

However, dental implants can only be placed if there is sufficient bone to encase the implant so that a direct interface between the implant surface and bone can be achieved. Frequently following resective surgery, insufficient bone volume remains and bony reconstruction of the surgical defect is required to enable successful dental implant placement [9]. Patients are commonly reconstructed with either a non-vascularised bone graft or a composite free flap. A non-vascularised bone graft is a free piece of non-vascularised bone (or bone substitute) that is placed in the tissues. A free flap is a vascularised piece of 
bone (pedicled), which is being increasingly used to reconstruct tumour patients.

High 'survival' and 'success' rates have been reported in the literature for dental implants placed into autogenous bone grafts in healthy patients but notably the success rates remain lower for implants placed into healthy native bone $[10,11]$. With the increasing use of complex reconstructive techniques in rehabilitation following $\mathrm{H} \& \mathrm{~N}$ cancer and the placement of dental implants into transported bone, there is a need to appraise the highly varied evidence that is currently available in order to help inform clinical decision making.

\section{Objectives}

It is the aim of this systematic review to evaluate the survival of dental implants placed into autogenous bone grafts, in $\mathrm{H} \& \mathrm{~N}$ oncology patients.

\section{Methods}

\section{Protocol}

The Preferred Reporting Items for Systematic Reviews and Meta-Analyses (PRISMA) [12,13] for describing and summarising the results of our review was used $[12,13]$.

A quality assessment of all selected full-text articles was performed using the Methodological Index for NonRandomized Studies (MINORS) [14] assessment tool to assess the risk of bias of the included studies. The MINORS scoring list consists of 12 items, eight apply to non-comparative studies, and a further four apply to comparative studies. Items are scored as 0 (not reported), 1 (reported but inadequate), and 2 (reported and adequate) with this then totalled up to give a score with the higher scores representing a reduced risk of bias [14]. This was chosen over the Cochrane collaborations' tool for assessing risk of bias for randomised controlled studies since none of the studies included were randomised control trials.

\section{Eligibility criteria \\ Inclusion criteria}

Studies that met the following criteria where included:

1. Dental implant placement into patients with cancer of the H\&N.

2. Dental implants placed into autogenous bone grafts.

3. Studies performed on humans.

4. Patients over 18 years old, or if there are patients under 18 years old within the study that these patients and their data can be removed from the analysis.

5. English language articles.

6. Any study design reporting on at least 35 dental implants or 20 patients who have had implants placed into autogenous bone.
7. Data related to implant number and implant survival in autogenous bone grafts that was either directly reported or can be calculated from data within the study.

\section{Exclusion criteria}

Studies were excluded if they met the following criteria:

1. Studies that reported on craniofacial or extra-oral implants only.

2. No reported implant survival or an inability to calculate implant number or survival from reported data.

3. Studies reporting on patients under 18 years old where there no ability to remove these patients and their data from the analysis.

4. Laboratory or animal-based studies.

5. Studies with less than 20 patients or 35 dental implants placed into autogenous bone grafts.

6. Review articles.

\section{Information sources}

Four electronic databases were used to systematically search the available literature: (1) The National Library of Medicine (MEDLINE via PubMed), (2) EMBASE, (3) Cochrane Central Register of Controlled Trials and (4) Science Direct. The searches were limited to studies involving human subjects and publication dates from January 1980 to August 2017 that satisfied the inclusion criteria.

\section{Search}

The following search terms were used: Population: $(<[$ text words] dental implant OR dental implant* OR oral implant OR oral implants OR osseointegrated implants OR endosseous implant OR dental implantation $<[\mathrm{MeSH}$ terms/all subheadings] AND ( $<$ [text words] head neck OR squamous cell carcinoma OR oncology OR tumour OR cancer OR malignant OR neoplasm $<[\mathrm{MeSH}$ terms/all subheadings] AND Intervention: free flap OR vascularized flap OR hard tissue graft OR micro vascularized flap OR micro anastomosed flap OR anastomosed flap OR native bone OR DCIA OR deep circumflex iliac artery OR radial OR scapula OR fibula OR iliac OR rib OR costochondral $<$ [MeSH terms/all subheadings $]$.

\section{Study selection}

Two reviewers (DL and RK) carried out the primary search by screening independently the titles and abstracts and identifying the studies appearing to meet the inclusion criteria. Studies with insufficient information in the title and abstract to make a clear decision were identified and the full paper was reviewed. Those studies selected for evaluation of the full manuscript were carried out independently by the same reviewers who determined the final 
inclusion. Any disagreement was resolved by discussion with a third independent reviewer (OA). The reasons for rejecting studies at this or subsequent stages were recorded.

\section{Data collection process}

Two reviewers (DL and RK) then independently extracted the data using a bespoke data extraction form. Any disagreement was resolved by discussion with a third reviewer (OA). Studies with missing or incomplete data were excluded and reference lists of the selected studies were checked for cross-references to search for papers that might meet the eligibility criteria for inclusion.

\section{Data items}

Data was collected for implant survival, implant success, implant failure, implant complications, surgical implant placement protocol, implant system used, clinical followup, how the author defined success/survival, the type of autogenous bone graft, implant site, the prosthodontic rehabilitation and type of cancer, and the use of radiotherapy were documented where possible.

\section{Risk of bias in individual studies}

A quality assessment of all selected full-text articles was performed using the Methodological Index for NonRandomised Studies (MINORS) [14] assessment tool.

\section{Summary measures}

The main outcome measure was implant survival. This review will define implant survival as an implant still in situ that has not been removed or lost at the census date and thus implant failure defined as an implant that has been removed or lost and is no longer in situ.

\section{Synthesis of results}

The survival and success figures documented where possible are taken directly from the study; however, where the study did not specifically document the survival or success of implants placed into autogenous bone as a percentage, this was calculated from the data provided (as a function of surviving or successful implants from total reported as placed), and studies that lacked data to calculate this were rejected as part of the secondary screening process.

\section{Additional analyses}

No further analyse was carried out.

\section{Results}

\section{Study selection}

Searches of EMBASE, the Cochrane Central Register of Controlled Trials, Science Direct and MEDLINE generated 619 articles. After duplicate articles were removed, 566 unique articles were remaining. After the review of the titles and abstracts, 151 articles were accepted for further consideration, and 415 were rejected. After the full text was attained and reviewed for the 151 articles, 131 articles were rejected leaving 20 articles to be included in the systematic review (Fig. 1).

\section{Study characteristics}

The following data was extracted from the studies; study design, centres (single vs multiple centres), patient demographics (patient age, $\mathrm{H} \& \mathrm{~N}$ cancer diagnosis), treatment

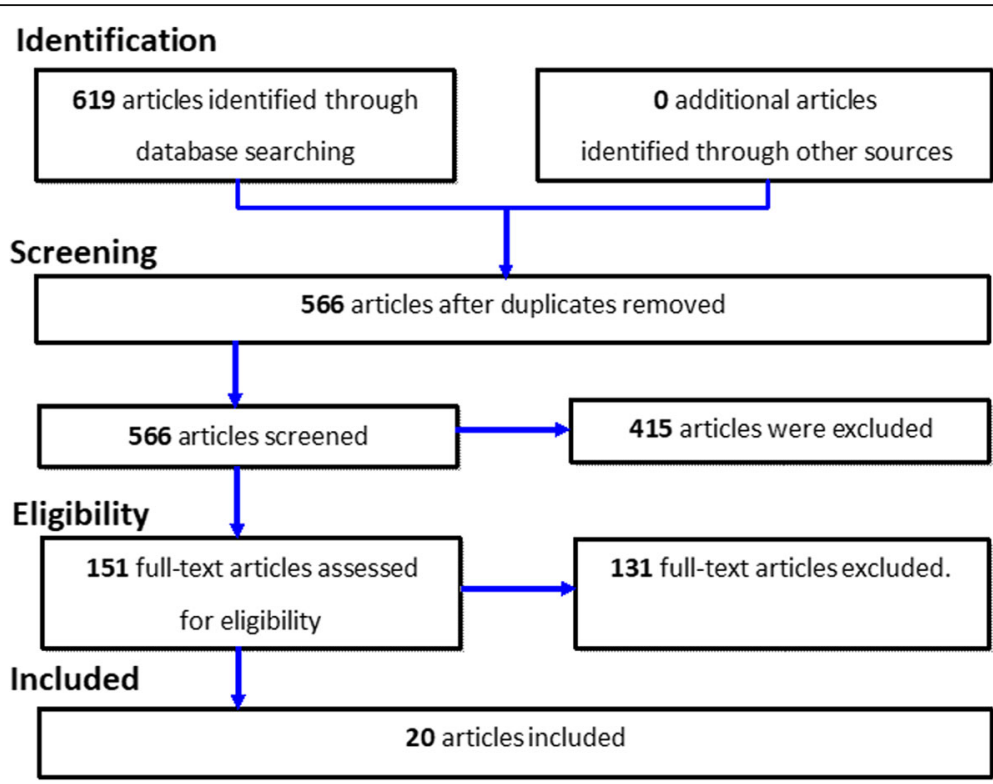

Fig. 1 Flow chart of study selection procedure 
modalities (surgery, radiotherapy, chemotherapy), donor site of autogenous bone graft, outcome measures, implant details (implant system, implant number, implant site, type of bone implant placed into (non-vascularised vs vascularised/ free flap), implant placement surgical protocol implant survival/success/failure figures), implant definitions (implant survival/success/failure), type of prosthetic rehabilitation (fixed vs removable), and any reported complications.

\section{Risk of bias within studies}

There were varying scores attained by the studies using the MINORS assessment tool, ranging from $7 / 16$ to $13 / 16$ representing varying degrees of bias within the studies (Table 1).

\section{Statistical analysis}

Due to the lack of controlled studies and the heterogeneity of the studies concerning patient selection, surgical protocols, implant loading, follow-up and prosthetic rehabilitation, implant survival definitions and figures, measurement protocols, and inconsistency in data reporting a formal meta-analysis would be statistically inappropriate and was not conducted. Descriptive statistics where used to interpret and present the data from these studies.

\section{Results of the studies}

Descriptive data extraction was carried out for the 20 studies and is summarised in Tables 1 and 2. All studies were retrospective observational studies in design with the majority undertaken at single centres; however, for 3 studies, this was unclear (Schultes et al. [15], Yerit et al. [16], Linsen et al. [17]). These 20 studies were published over a range of 21 years (1996 to 2017) and provide cumulative data on 1905 implants placed into autogenous bone grafts in $\mathrm{H} \& \mathrm{~N}$ cancer patients with both benign and malignant tumours being reported. The exact patient number for this intervention within some of the studies was unclear as a result of the studies reporting on implant rather than patient number or there was an inability to identify which population received dental implants to identify patient numbers. One study (Chiapasco et al. [18]) included reported on patients under 18 years old (two patients in total); however, these patients and their data could be removed from the analysis.

Implants were placed into both vascularised and nonvascularised autogenous bone grafts, with a number of donor sites being reported. (Tables 2 and 3) These implants were placed in a variety of intra-oral sites with implants placed into autogenous bone grafts within the mandible reported in eight studies and bi-maxillary placement in nine studies, and in three studies, it was unknown where the implant fixtures were placed other than that they were placed into autogenous bone grafts (Linsen et al. [17], Fenlon et al.
[19], Ch'ng et al. [20]). There were no studies where implants were placed solely in the reconstructed maxilla.

Radiotherapy to the autogenous bone graft/implant site was reported in 16 studies. Two studies (Wang et al. [21], Zou et al. [22]) reported that radiotherapy was not carried out on the study population and in 1 study (Yerit et al. [16]) bone graft sites were not irradiated. One study (Chiapasco et al. 2008 [23]) failed to report whether radiotherapy was carried out or not on the study population. Of 20 studies included in the systematic review, only 7 studies reported on outcomes related to implant survival in irradiated autogenous bone grafts (Barrowman et al. [7], Fenlon et al. [19], Ch'ng et al. [20], Buddula et al. [24], Fierz et al. [25], Teoh et al. [26], Burgess et al. [27]).

The surgical and loading implant protocols were reported in 17 studies with no description given in 3 studies (Barrowman et al. [7], Fierz et al. [25], Hessling et al. [28]). The implant placement protocols were diverse with variables including the use of surgical templates/guides, primary and/or secondary implant placement following autogenous bone grafting, and immediate and/or delayed implant loading; however, the majority of the studies reported on delayed implant placement following initial healing of the transported bone graft and delayed loading of the implant fixtures. Six studies reported primary implant placement (Fenlon et al. [19], Ch'ng et al. [20], Zou et al. [22], Burgess et al. [27], Wu et al. [30], Watzinger et al. [29],) and one study reported immediate implant loading (Chiapasco et al. [18]). Additional procedures were also reported which include removal of reconstruction plates and screws at the time of implant placement, bone condensing to enhance the bone density, and further periimplant surgery in the form of debulking of soft tissues, gingivoplasty/vestibuloplasty and free mucosal grafts to optimise the soft tissue conditions (Table 1). Prosthodontic reconstruction of the implant fixture was reported in 15 of the studies which included fixed and removable prosthesis and is summarised in Table 1.

\section{Overall implant survival}

The overall implant survival of implants placed into autogenous bone grafts varied highly (both at implant and patient levels) between the included studies ranging from $100 \%$ with a mean follow-up of 3.5 years \pm 0.3 years in a study by Wang et al. [30] to $54 \%$ with a mean follow-up 5 . 4 years \pm 3.2 years by Yerit et al. [16].,(at an implant level) (Table 2).

Eleven studies compared implant survival in autogenous bone grafts to that in native bone within their studies. Nine of these studies (Barrowman et al. [7], Yerit et al. [16], Linsen et al. [17], Fenlon et al. [19], Ch'ng et al. [20], Hessling et al. [28], Watzinger et al. [29], Shaw et al. [31], Klein et al. [32]) reported higher implant failure rates 


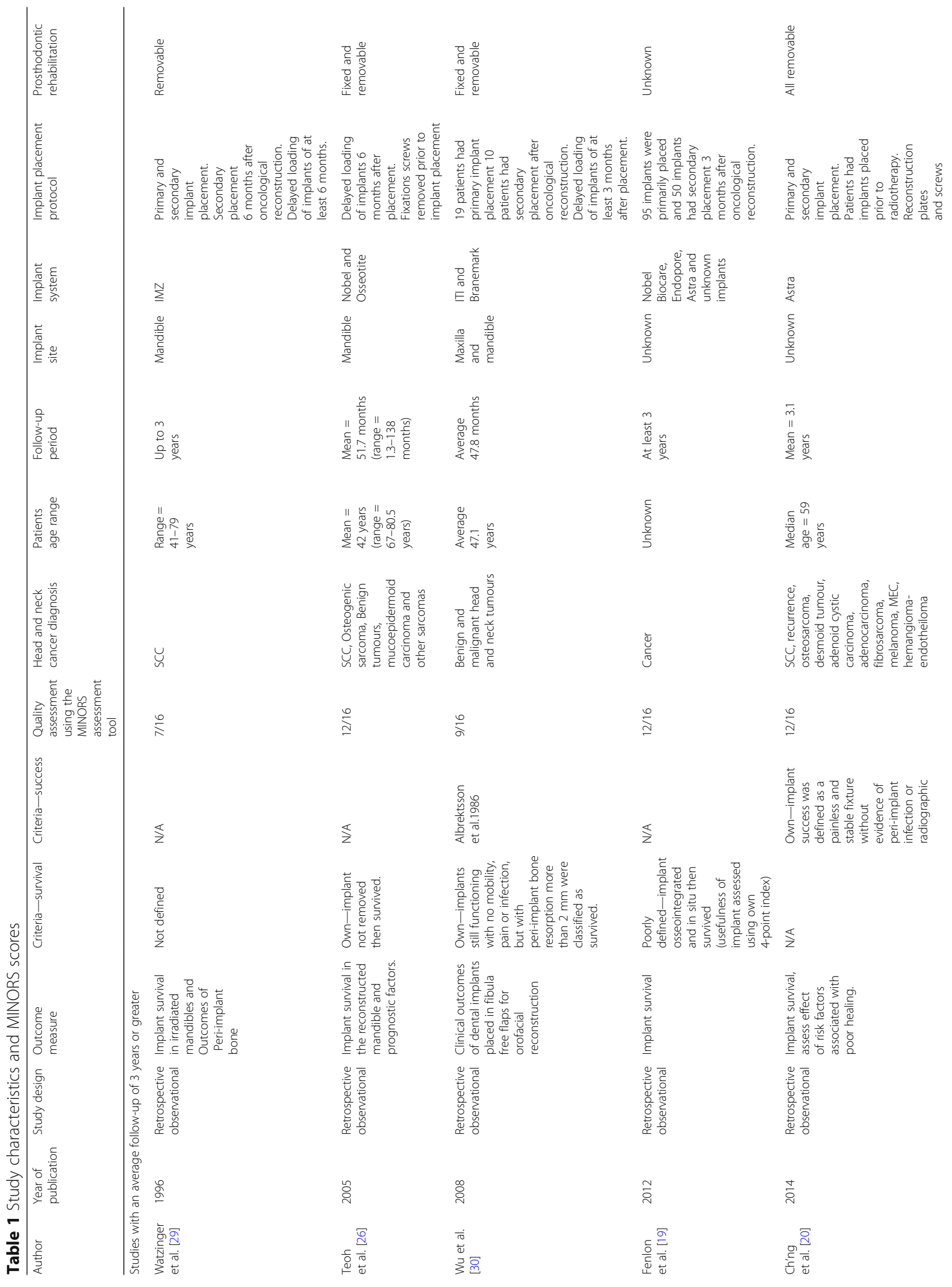




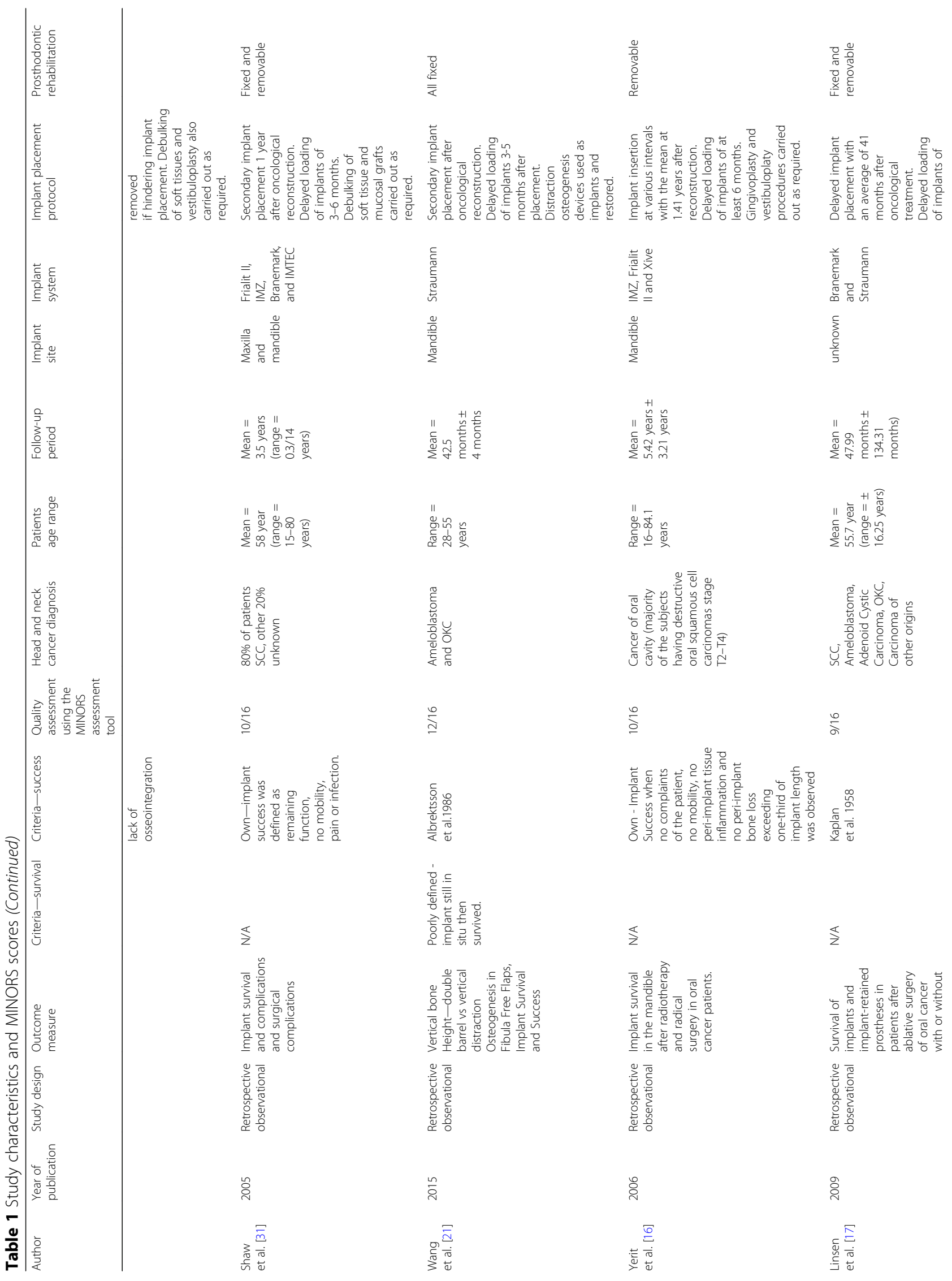




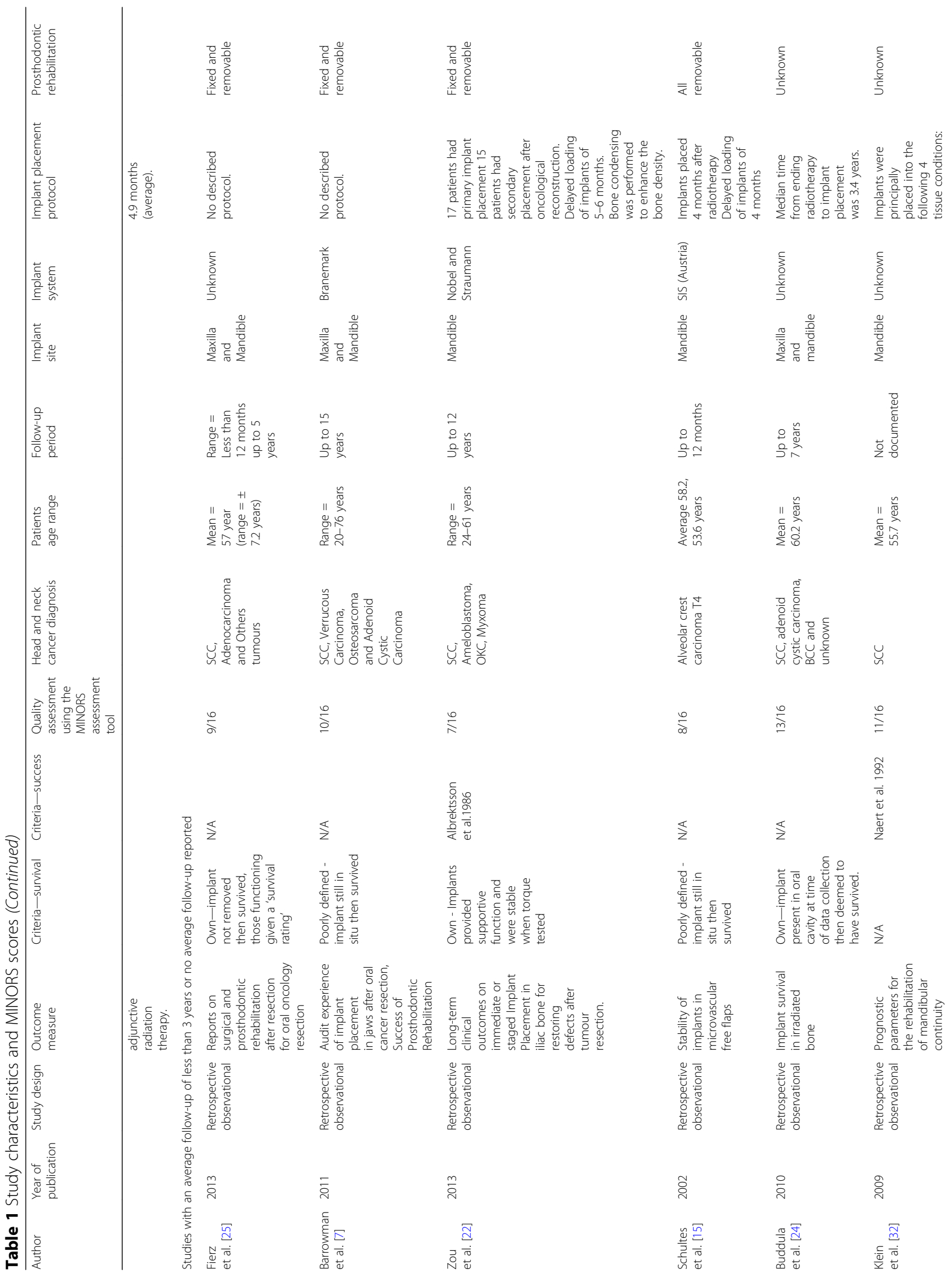




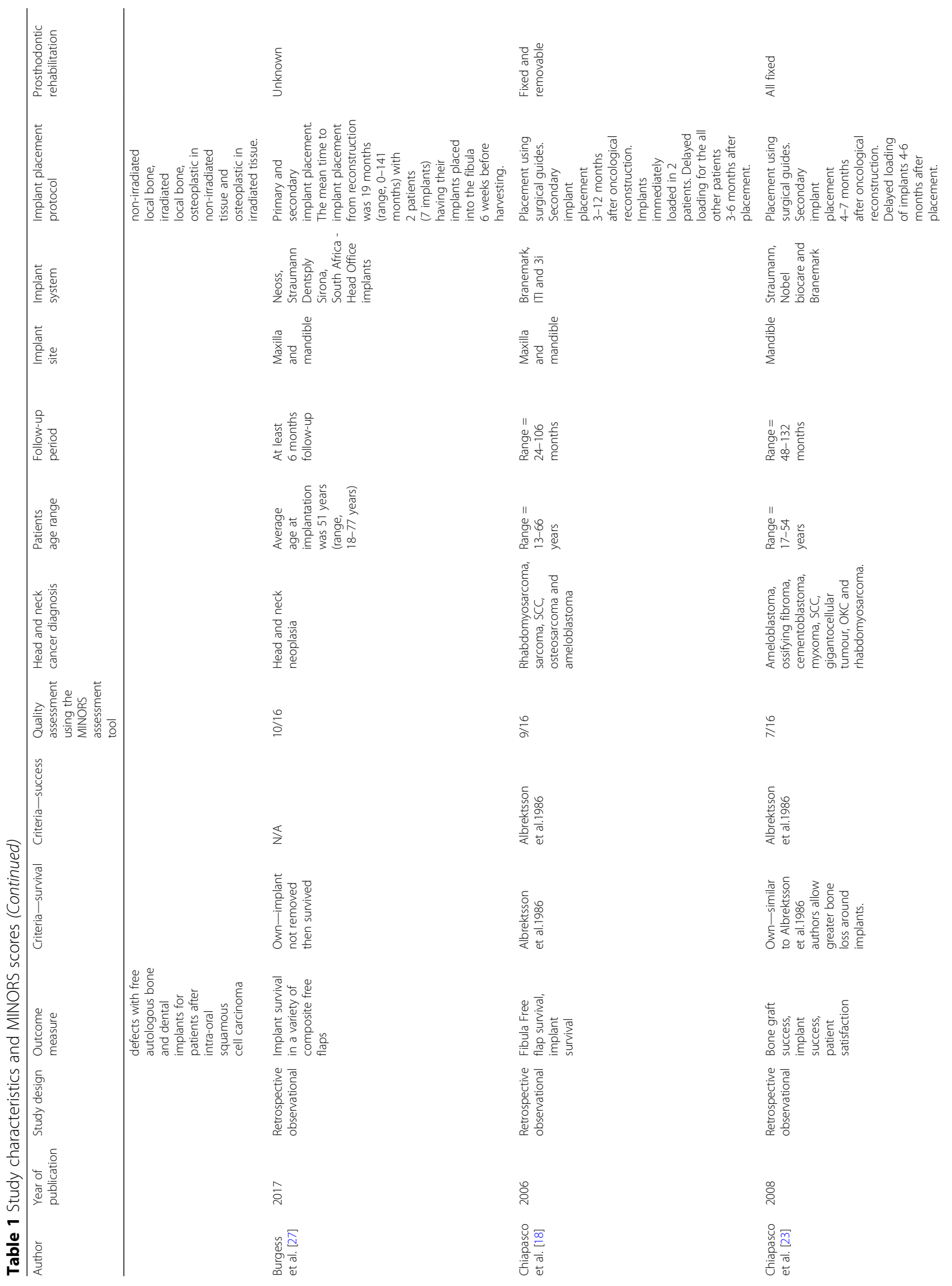




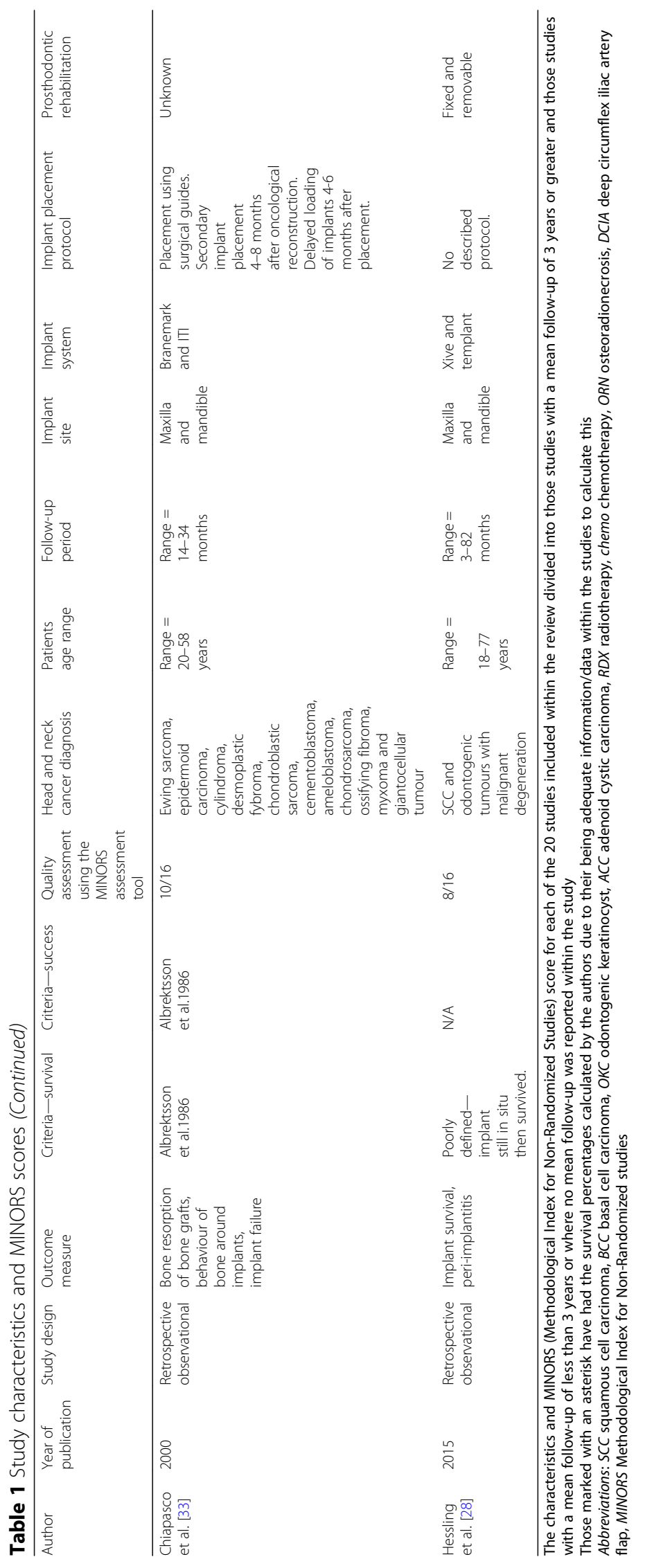




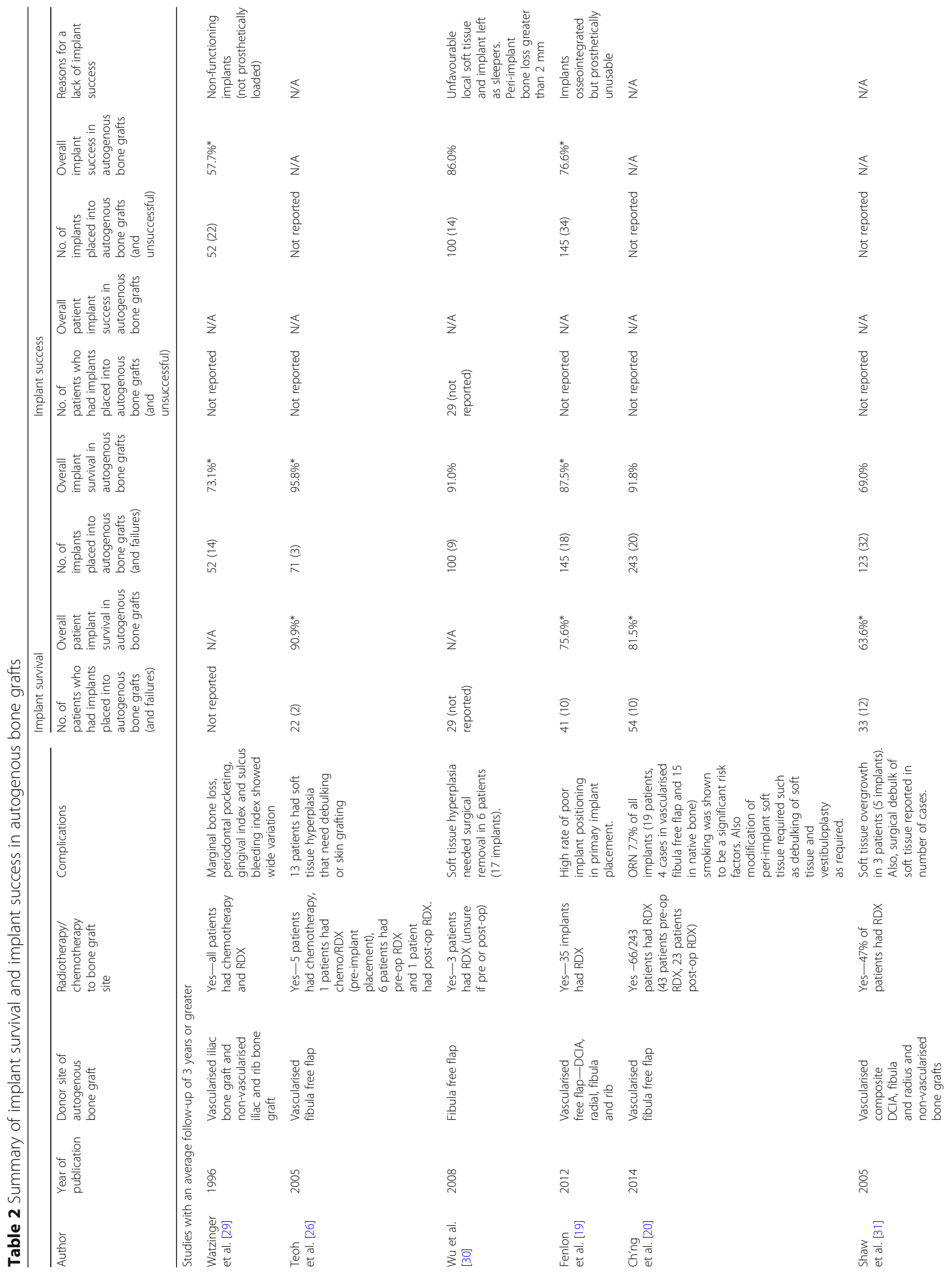




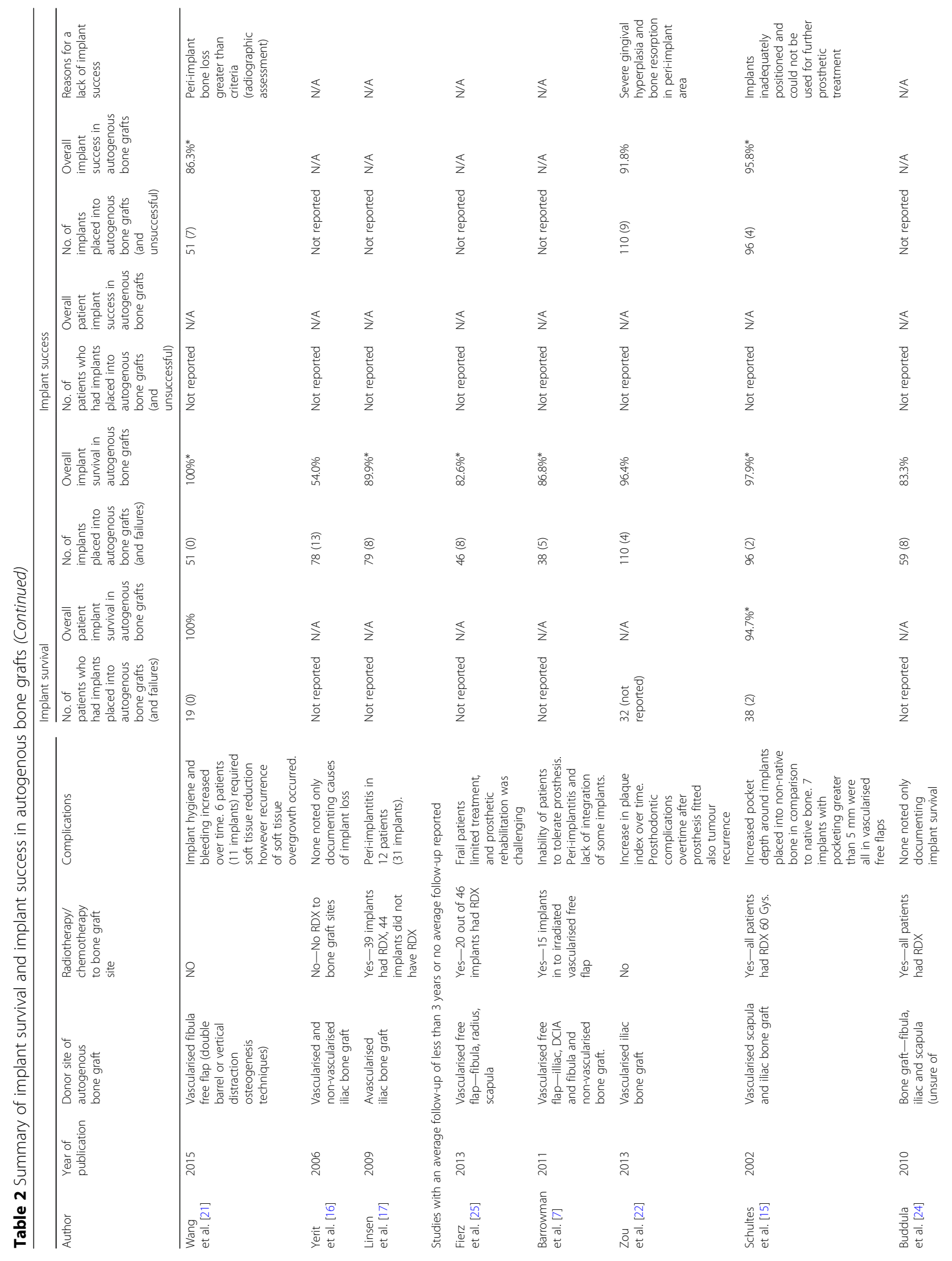




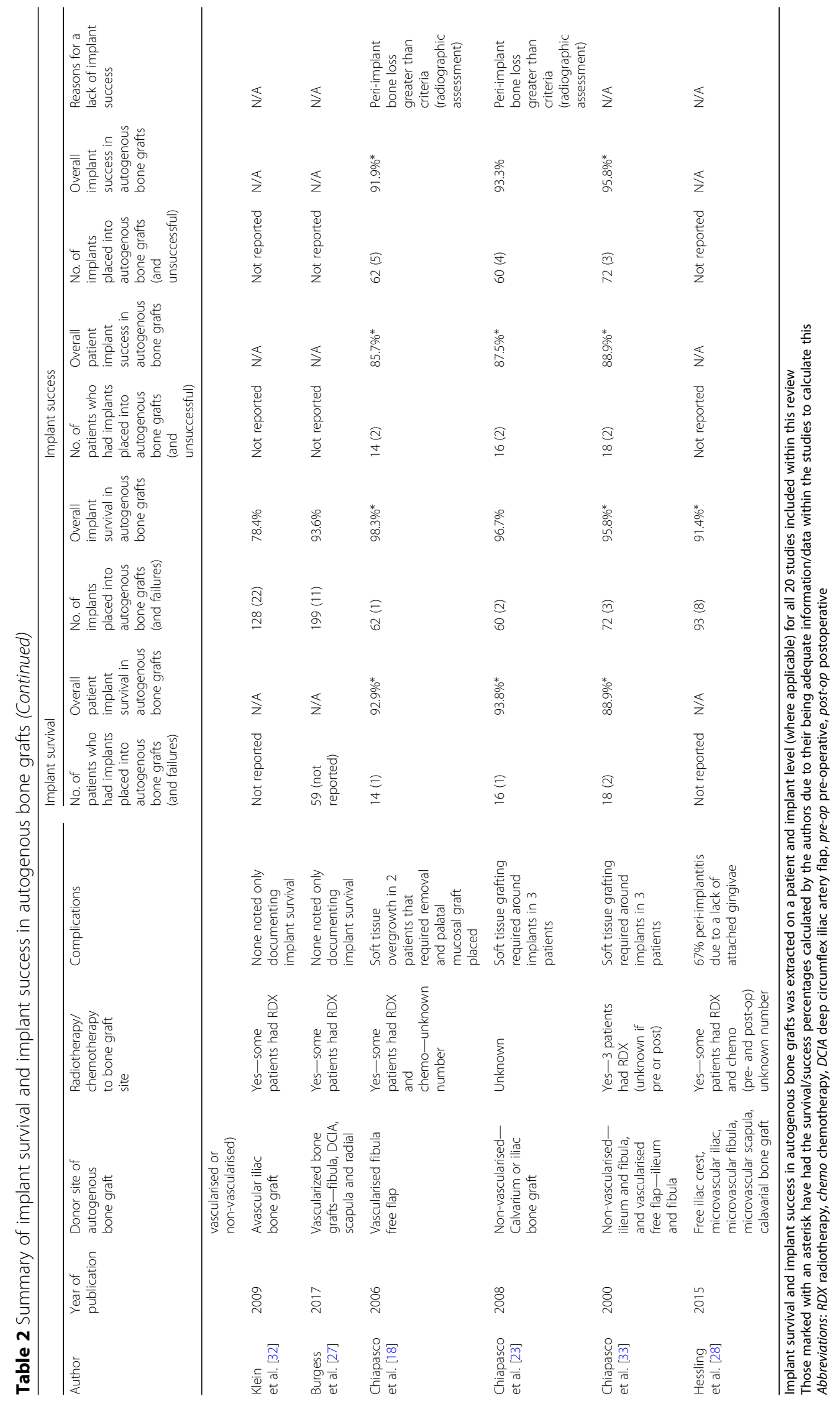


Table 3 Implant survival in autogenous bone grafts placed in vascularised and non-vascularised bone grafts

\begin{tabular}{|c|c|c|c|c|c|c|c|c|c|}
\hline \multirow[b]{2}{*}{ Author } & \multirow[b]{2}{*}{$\begin{array}{l}\text { Year of } \\
\text { publication }\end{array}$} & \multicolumn{4}{|c|}{ Non-vascularised bone graft } & \multicolumn{4}{|c|}{ Vascularised bone graft } \\
\hline & & $\begin{array}{l}\text { No. of } \\
\text { patients who } \\
\text { had implants } \\
\text { placed into } \\
\text { non-vascularised } \\
\text { autogenous } \\
\text { bone grafts } \\
\text { (and failures) }\end{array}$ & $\begin{array}{l}\text { Overall } \\
\text { patient implant } \\
\text { survival in } \\
\text { non-vascularised } \\
\text { autogenous } \\
\text { bone grafts }\end{array}$ & $\begin{array}{l}\text { No. of implants } \\
\text { placed into } \\
\text { non-vascularised } \\
\text { autogenous } \\
\text { bone grafts } \\
\text { (and failures) }\end{array}$ & $\begin{array}{l}\text { Overall } \\
\text { implant } \\
\text { survival in } \\
\text { non-vascularised } \\
\text { autogenous } \\
\text { bone grafts }\end{array}$ & $\begin{array}{l}\text { No. of } \\
\text { patients who } \\
\text { had implants } \\
\text { placed into } \\
\text { vascularized } \\
\text { autogenous } \\
\text { bone grafts } \\
\text { (and failures) }\end{array}$ & $\begin{array}{l}\text { Overall } \\
\text { patient } \\
\text { implant } \\
\text { survival in } \\
\text { vascularised } \\
\text { autogenous } \\
\text { bone grafts }\end{array}$ & $\begin{array}{l}\text { No. of } \\
\text { implants } \\
\text { placed into } \\
\text { vascularised } \\
\text { autogenous } \\
\text { bone grafts } \\
\text { (and failures) }\end{array}$ & $\begin{array}{l}\text { Overall } \\
\text { implant } \\
\text { survival in } \\
\text { vascularisec } \\
\text { autogenou } \\
\text { bone grafts }\end{array}$ \\
\hline \multicolumn{10}{|c|}{ Studies with an average follow-up of 3 years or greater } \\
\hline Watzinger et al. [29] & 1996 & Not reported & N/A & $33(13)$ & $60.6 \% *$ & Not reported & N/A & $19(1)$ & $94.7 \% *$ \\
\hline Teoh et al. [26] & 2005 & N/A & N/A & N/A & N/A & $22(2)$ & $90.9 \% *$ & $71(3)$ & $95.8 \% *$ \\
\hline Wu et al. [30] & 2008 & N/A & N/A & N/A & N/A & 29 (not reported) & N/A & $100(9)$ & $91 \%$ \\
\hline Fenlon et al. [19] & 2012 & N/A & N/A & N/A & N/A & $41(10)$ & $75.6 \% *$ & $145(18)$ & $87.5 \%^{*}$ \\
\hline Ch'ng et al. [20] & 2014 & N/A & N/A & N/A & $\mathrm{N} / \mathrm{A}$ & $54(10)$ & $81.5 \%^{*}$ & $243(20)$ & $91.8 \%$ \\
\hline Shaw et al. [31] & 2005 & $2(1)$ & $50 \% *$ & $8(2)$ & $75 \% *$ & $31(11)$ & $64.5 \%^{*}$ & $115(30)$ & $73.9 \% *$ \\
\hline Wang et al. [21] & 2015 & N/A & N/A & N/A & N/A & $19(0)$ & $100 \%$ & $51(0)$ & $100 \%{ }^{*}$ \\
\hline Yerit et al. [16] & 2006 & Not reported & N/A & Not reported & N/A & Not reported & N/A & Not reported & N/A \\
\hline Linsen et al. [17] & 2009 & Not reported & N/A & 79 (8) & $89.9 \%^{*}$ & N/A & $\mathrm{N} / \mathrm{A}$ & N/A & $\mathrm{N} / \mathrm{A}$ \\
\hline \multicolumn{10}{|c|}{ Studies with an average follow-up of less than 3 years or no average follow-up reported } \\
\hline Fierz et al. [25] & 2013 & N/A & N/A & N/A & N/A & Not reported & N/A & Not reported & N/A \\
\hline Barrowman et al. [7] & 2011 & Not reported & N/A & $6(0)$ & $100 \%^{*}$ & Not reported & N/A & $32(5)$ & $84.4 \%^{*}$ \\
\hline Zou et al. [22] & 2013 & N/A & N/A & N/A & N/A & 32 (not reported) & N/A & $110(5)$ & $96.4 \%$ \\
\hline Schultes et al. [15] & 2002 & N/A & N/A & N/A & N/A & $38(2)$ & $94.7 \%^{*}$ & $96(2)$ & $97.9 \% *$ \\
\hline Buddula et al. [24] & 2010 & Not reported & N/A & Not reported & N/A & Not reported & $\mathrm{N} / \mathrm{A}$ & Not reported & N/A \\
\hline Klein et al. [32] & 2009 & Not reported & N/A & $128(22)$ & $82.8 \%^{*}$ & N/A & $\mathrm{N} / \mathrm{A}$ & $\mathrm{N} / \mathrm{A}$ & $\mathrm{N} / \mathrm{A}$ \\
\hline Burgess et al. [27] & 2017 & N/A & N/A & N/A & $\mathrm{N} / \mathrm{A}$ & 59 (not reported) & N/A & $199(11)$ & $93.6 \%$ \\
\hline Chiapasco et al. [18] & 2006 & N/A & N/A & N/A & $\mathrm{N} / \mathrm{A}$ & $14(1)$ & $92.9 \% *$ & $62(1)$ & $98.3 \%^{*}$ \\
\hline Chiapasco et al. [23] & 2008 & $16(1)$ & $93.8 \% *^{*}$ & 60 (2) & $96.7 \% *$ & $\mathrm{~N} / \mathrm{A}$ & $\mathrm{N} / \mathrm{A}$ & N/A & N/A \\
\hline Chiapasco et al. [33] & 2000 & $10(1)$ & $90 \% *$ & $41(2)$ & $95.1 \%^{*}$ & $8(1)$ & $87.5 \%^{*}$ & $31(1)$ & $96.8 \%{ }^{*}$ \\
\hline Hessling et al. [28] & 2015 & Not Reported & N/A & $62(4)$ & $93.5 \% *^{*}$ & Not reported & N/A & $31(4)$ & $87.1 \%^{*}$ \\
\hline
\end{tabular}

Implant survival in autogenous bone grafts was extracted on a patient and implant level (where applicable) for all 20 studies included within this review that specifically reported on implant survival in either vascularised or non-vascularised autogenous bone grafts

Those marked with an asterisk have had the survival percentages calculated by the authors due to their being adequate information/data within the studies to calculate this

within autogenous bone grafts than those within implants placed into the native bone; however, two studies (Buddula et al. [24], Teoh et al. [26]) reported no significant difference.

\section{Autogenous bone graft type and implant survival}

Seventeen studies reported on the specific bone graft type (non-vascularised or vascularised) into which the implants were placed. In the remaining three studies (Buddula et al. [24], Fierz et al. [25], Yerit et al. [16]), this distinction was not possible.

Of these 17 studies, 8 studies reported on implant survival in non-vascularised bone grafts and 14 studies reported on implant survival in vascularised bone grafts with 5 studies (Barrowman et al. [7], Hessling et al. [28], Watzinger et al. [29], Shaw et al. [31], Chiapasco et al. [33]), therefore reporting on implant survival in both non-vascularised and vascularised bone grafts within their study (Table 3). Implant survival appears to be higher for those implants placed into vascularised bone grafts in comparison to non-vascularised bone grafts. Of the five studies reporting on both vascularised and nonvascularised bone grafts, three of these studies (Barrowman et al. [7], Watzinger et al. [29], Chiapasco et al. [33]) reported higher implant survival in vascularised bone grafts whereas the other two studies (Hessling et al. [28], Shaw et al. [31]) reported higher implant survival in nonvascularised bone grafts. Shaw et al. [31] reported that implants placed into 'vascularized bone graft were superior to non-vascularized bone. In particular, those implants in composite radial forearm flaps performed badly. With the proportion of patients with implant loss in these bone flaps within their study being $27 \%$ in iliac crest, $33 \%$ in fibula, and $100 \%$ in radius and that implants placed in composite fibula and iliac crest flaps performed approximately as well as in native maxilla within their study' [31]. 
Twelve studies reported on the use of more than one autogenous bone graft donor site within their study (Barrowman et al. [7], Schultes et al. [15], Yerit et al. [16], Fenlon et al. [19], Chiapasco et al. [23], Buddula et al. [24], Fierz et al. [25], Burgess et al. [27], Hessling et al. [28], Watzinger et al. [29], Shaw et al. [31] and Chiapasco et al. [33]); of these, five studies reported on the effect of the autogenous bone graft donor site on implant survival. Two studies (Fenlon et al. [19], Burgess et al. [27]) reported no significant effect on implant survival in varying graft donor sites; however, three studies (Hessling et al. [28], Shaw et al. [31], Chiapasco et al. [33]) reported varying implant survival rates within different autogenous bone grafts but only one study (Hessling et al. [28]) reported that implant loss was significant with this being for implants placed into fibula bone grafts. Shaw et al,. [31] reporting that implants placed into 'vascularized bone graft were superior to non-vascularized bone. In particular, those implants in composite radial forearm flaps performed badly. With the proportion of patients with implant loss in these bone flaps within their study being $27 \%$ in iliac crest, $33 \%$ in fibula, and $100 \%$ in radius and that implants placed in composite fibula and iliac crest flaps performed approximately as well as in native maxilla within their study' [31].

\section{Radiotherapy and implant survival}

Seven studies reported on outcomes related to implant survival in irradiated autogenous bone grafts (Barrowman et al. [7], Fenlon et al. [19], Ch'ng et al. [20], Buddula et al. [24], Fierz et al. [25], Teoh et al. [26], Burgess et al. [27]) (Table 4). One study reported solely on irradiated patients (Buddula et al. [24]) the other six studies (Barrowman et al. [7], Fenlon et al. [19], Ch'ng et al. [20], Fierz et al. [25], Teoh et al. [26], Burgess et al. [27]) reported on both irradiated and non-irradiated patients. These six studies (Barrowman et al. [7], Fenlon et al. [19], Ch'ng et al. [20], Fierz et al. [25], Teoh et al. [26], Burgess et al. [27]) all reported higher implant failure (at an implant and a patient level (where applicable)) of implants placed into autogenous bone grafts in irradiated patients in comparison to those patients who did not received radiotherapy (Table 4).

All of these studies (Barrowman et al. [7], Fenlon et al. [19], Ch'ng et al. [20], Fierz et al. [25], Teoh et al. [26], Burgess et al. [27]) reported on the deleterious effect of radiotherapy on implant survival in autogenous bone grafts within their studies and was found to be statistically significant in two studies (Fenlon et al. [19], Ch'ng et al. [20]) with Fenlon [19] reporting a close correspondence of implant survival (in vascularised free composite grafts) and an absence of radiotherapy using a multiple correspondence analysis and Ch'ng et al. [20] who reported a statistical significance associated with higher implant failure in irradiated fibula free flaps in comparison to non- irradiated fibula free flaps $(P=0.041)$. However, in two studies (Teoh et al. [26], Burgess et al. [27]), no statistical significance was found despite higher implant failure.

\section{Primary and secondary implant placement and implant survival}

Six studies clearly reported the use of both primary and secondary implant placement within their study (Fenlon et al. [19], Ch'ng et al. [20], Zou et al. [22], Burgess et al. [27], Watzinger et al. [29], Wu et al. [30]); however, only one study (Fenlon et al. [19]) reported on implant survival in primary and secondary implant placement within autogenous bone grafts. Felon et al. [19] reported on implant survival in immediate vs delayed placement of the implant fixtures into free vascularised grafts and found that implant survival of immediately placed implants was significantly worse than that of implants placed after a delay of 3 months in free vascularized grafts.

\section{Cancer diagnosis and implant survival}

With regards to cancer type (malignant vs benign), three studies (Schultes et al. [15], Watzinger et al. [29], Klein et al. [32]) reported exclusively on implant survival in patients with malignant $\mathrm{H} \& \mathrm{~N}$ cancers with varying implant survival rates being reported, whilst one study reported exclusively on benign $H \& N$ cancer patients (Wang et al. [21]) with a $100 \%$ implant survival rate being reported (Table 2). Two studies (Fenlon et al. [19], Burgess et al. [27]) provided non-descriptive terms (cancer, head and neck neoplasia) for the type of $H \& N$ cancer of the patients within their studies and therefore differentiation between benign and malignant disease could not be made. The other 14 studies reported on both malignant and benign $\mathrm{H} \& \mathrm{~N}$ cancers; however, the implant survival data was not reported or presented in a way in which comparison of implant survival in patients with malignant or benign $H \& N$ cancers could be made.

\section{Implant survival and Peri-implant soft tissue}

Only one study (Linsen et al. [17]) reported on the effect of the peri-implant soft tissue and implant survival of implants placed into autogenous bone grafts. Linsen et al. [17] reported a higher implant failure of implants placed into bone and soft tissue grafts in comparison to implants placed into a bone grafts with residual soft tissues. This difference, however, was not found to be statistically significant $(p=0.436)$.

In the other 19 studies, the effect of the peri-implant soft tissue was not directly reported as being a factor for implant survival. However, implant success appeared to be significantly affected by the peri-implant soft tissues (see the "Implant survival and Implant Success" and "Complications" sections - for further details). 
Table 4 Implant survival in autogenous bone grafts of irradiated \& non-irradiated patients

\begin{tabular}{|c|c|c|c|c|c|c|c|c|c|}
\hline \multirow{2}{*}{$\overline{\text { Author }}$} & \multirow[b]{2}{*}{$\begin{array}{l}\text { Year of } \\
\text { publication }\end{array}$} & \multicolumn{4}{|l|}{$\mathrm{RDX}$} & \multicolumn{4}{|l|}{ No RDX } \\
\hline & & $\begin{array}{l}\text { No. of } \\
\text { implants } \\
\text { placed into } \\
\text { autogenous } \\
\text { bone grafts } \\
\text { with RDX } \\
\text { (and failures) }\end{array}$ & $\begin{array}{l}\text { Overall } \\
\text { implant } \\
\text { survival } \\
\text { of implants } \\
\text { placed into } \\
\text { autogenous } \\
\text { bone grafts } \\
\text { with RDX }\end{array}$ & $\begin{array}{l}\text { No. of } \\
\text { patients } \\
\text { who had } \\
\text { implants } \\
\text { placed into } \\
\text { autogenous } \\
\text { bone grafts } \\
\text { with RDX } \\
\text { (and failures) }\end{array}$ & $\begin{array}{l}\text { Patient } \\
\text { based } \\
\text { implant } \\
\text { survival } \\
\text { of implant } \\
\text { placed into } \\
\text { autogenous } \\
\text { bone grafts } \\
\text { with RDX }\end{array}$ & $\begin{array}{l}\text { No. of } \\
\text { implants } \\
\text { placed into } \\
\text { autogenous } \\
\text { bone grafts } \\
\text { with no RDX } \\
\text { (and failures) }\end{array}$ & $\begin{array}{l}\text { Overall } \\
\text { implant } \\
\text { survival of } \\
\text { implants } \\
\text { placed into } \\
\text { autogenous } \\
\text { bone grafts } \\
\text { with no RDX }\end{array}$ & $\begin{array}{l}\text { No. of } \\
\text { patients } \\
\text { who had } \\
\text { implants } \\
\text { placed into } \\
\text { autogenous } \\
\text { bone grafts } \\
\text { with no RDX } \\
\text { (and failures) }\end{array}$ & $\begin{array}{l}\text { Patient-based } \\
\text { implant survival } \\
\text { of implant placed } \\
\text { into autogenous } \\
\text { bone grafts with } \\
\text { no RDX }\end{array}$ \\
\hline $\begin{array}{l}\text { Teoh et al. } \\
\text { [26] }\end{array}$ & 2005 & $14(2)$ & $85.7 \% *$ & $4(1)$ & $75 \% *$ & $57(1)$ & $98.2 \% *$ & $22(1)$ & $95.4 \% *$ \\
\hline $\begin{array}{l}\text { Fenlon } \\
\text { et al. [19] }\end{array}$ & 2012 & $35(15)$ & $57.1 \% *$ & $12(8)$ & $33.3 \% *$ & $110(3)$ & $97.3 \% *$ & $29(2)$ & $93.1 \% *$ \\
\hline $\begin{array}{l}\text { Ch'ng et al. } \\
{[20]}\end{array}$ & 2014 & $66(11)$ & $83.3 \% *$ & Not reported & $\mathrm{N} / \mathrm{A}$ & $177(9)$ & $94.9 \% *$ & Not reported & N/A \\
\hline $\begin{array}{l}\text { Fierz et al. } \\
\text { [25] }\end{array}$ & 2013 & $20(6)$ & $70.0 \% *$ & Not reported & $\mathrm{N} / \mathrm{A}$ & $26(2)$ & $92.3 \% *$ & Not reported & N/A \\
\hline $\begin{array}{l}\text { Barrowman } \\
\text { et al. [7] }\end{array}$ & 2011 & $15(5)$ & $66.7 \% *$ & Not reported & N/A & $23(0)$ & $100 \% *$ & Not reported & N/A \\
\hline $\begin{array}{l}\text { Buddula } \\
\text { et al. [24] }\end{array}$ & 2010 & $59(8)$ & $83.3 \%$ & Not reported & N/A & $\mathrm{N} / \mathrm{A}$ & N/A & N/A & N/A \\
\hline $\begin{array}{l}\text { Burgess } \\
\text { et al. [27] }\end{array}$ & 2017 & $45^{*}(7)$ & $84.4 \% *$ & Not reported & N/A & $154(4)$ & $97.4 \% *$ & Not reported & N/A \\
\hline
\end{tabular}

Implant survival in autogenous bone grafts of irradiated and non-irradiated patients was extracted on an implant and patient level (where applicable) for seven studies that reported on implant survival of implants placed in autogenous bone grafts

Those marked with an asterisk have had the survival percentages calculated by the authors due to their being adequate information/data within the studies to calculate this

Abbreviations: $R D X$ radiotherapy

\section{Implant survival and implant success}

In nine studies (Schultes et al. [15], Fenlon et al. [19], Wang et al. [21], Zou et al. [22], Chiapasco et al. [18], Chiapasco et al. [23], Watzinger et al. [29] Wu et al. [30], Chiapasco et al. [33]), both implant survival and success data was reported or provided (Table 2). When comparing implant survival and implant success in eight studies (Schultes et al. [15], Fenlon et al. [19], Wang et al. [21], Zou et al. [22], Chiapasco et al. [18], Chiapasco et al. [23], Watzinger et al. [29], Wu et al. [30], Chiapasco et al. [33]) implant success was found to be lower than implant survival but in one study (Chiapasco et al. [33]) implant survival and success were reported as being the same. The reasons for a lack of implant success within these eight studies (other than implant failure/loss) were related to excessive peri-implant bone loss in five studies (Wang et al. [21], Zou et al. [22], Chiapasco et al. [18], Chiapasco et al. [23], Wu et al. [30]), an inability to prosthetically restore the implants in four studies (Schultes et al. [15], Fenlon et al. [19], Watzinger et al. [29], Wu et al. [30]) and gingival hyperplasia in one study (Zou [22]). Six of these studies (Schultes et al. [15], Wang et al. [21], Zou et al. [22], Chiapasco et al. [18], Chiapasco et al. [23], Wu et al. [30]) reported some of this lack of success to the peri-implant soft tissue which was most frequently the soft tissue component of a combined bone and soft tissue free flap (most commonly the external skin).

\section{Complications}

A variety of implant-based complications were documented. Complications were often described within the study rather than being formal assessed, defined or used as outcome measures. Due to there being a lack of formal definition and variability in the documentation within the studies, the data cannot be considered robust to be collectively appraised but is described for information purposes. Common "complications" reported in the studies include soft tissue overgrowth/hyperplasia of the peri-implant tissues (Wang et al. [21], Chiapasco et al. [18], Teoh et al. [26], Wu et al. [30], Shaw et al. [31]), peri-implantitis and periodontal pocketing (Barrowman et al. [7], Schultes et al. [15], Linsen et al. [17], Burgess et al. [27], Hessling et al. [28]), the need for soft tissue debulking/modification around free flaps (Ch'ng et al. [20], Shaw et al. [31]) and the need for mucosal/soft tissue graft around implants to improve the soft tissue profile (Chiapasco et al. [23], Teoh et al. [26], Chiapasco et al. [33]). These peri-implant complications were most commonly seen when the soft tissue profile around the implant was related to a soft tissue graft and therefore did not have attached keratinised mucosa which is needed to provide a soft tissue profile that is conducive to peri-implant health. Other complications include poor oral hygiene (Wang et al. [21], Zou [22]), challenging 
prosthodontic rehabilitation/inability to tolerate the prosthesis provided (Barrowman et al. [7], Zou et al. [22], Fierz et al. [25]), poor implant position (Schultes et al. [15], Fenlon et al. [19], Watzinger et al. [29], Wu et al. [30]) and osteoradionecrosis (Ch'ng et al. [20]) (Table 2).

\section{Discussion}

\section{Summary of evidence}

Dental implants are now perceived to be a vital part of the clinician's armamentarium in the provision of oral and dental rehabilitation for patients with acquired deformity following management of their H\&N cancer, and therefore, this systematic review is relevant to clinicians and stakeholders involved in the treatment and management of $\mathrm{H} \& \mathrm{~N}$ cancer patients specifically with those involved in placing or utilising dental implants to assist in the dental/ oral rehabilitation of $\mathrm{H} \& \mathrm{~N}$ cancer patients.

The main findings from this systematic review did however identify, with the exception of a small number of studies, implant survival (at an implant level) in autogenous bone grafts was clinically promising (> 85\%); however, this appears to be lower than implants placed into the native bone in $H \& N$ cancer patients. Weak evidence was identified which suggests that radiotherapy is a prognostic factor affecting implant survival in this patient cohort; however, this has also been reported as having a detrimental effect on implant survival in the native bone within the literature [34]. The type of autogenous bone graft donor site and implant survival was also reviewed within the included studies that compared varying autogenous bone graft donor sites and implant survival. There is some weak evidence from these studies to suggest that implants placed into vascularised bone grafts appear to have a higher survival rate in comparison to non-vascularised bone grafts within this review. This evidence however is unreliable, due to the clear lack of studies reporting on implant survival in non-vascularised bone grafts and thus the subsequent number of implants and patients included within this review. Implant survival did not appear to be affected by the type of H\&N cancer type (malignant vs. benign); however, no studies within this review directly compared or enabled the authors of this manuscript to compare studies, and accordingly, no true conclusion can be made on this.

The implant placement protocol with regard to primary (immediate) or secondary (delayed) implant placement was also reviewed, and there is limited evidence from Fenlon et al. that implant failure is significantly worse in immediately placed implants in comparison with a delayed approach in free vascularized grafts.

Implant success was shown to be lower than implant survival and was related to peri-implant bone loss, periimplant hyperplasia and an inability to prosthetically restore the implants. This was most commonly related to combined bone and soft tissue grafts, specifically the soft tissue component. This soft tissue component provides a suboptimal soft tissue profile which could contribute to implant failure (as a result of peri-implantitis); however, well-designed long-term studies are needed to fully comprehend the effect on implant survival.

Implant complications were also noted specific to autogenous bone grafts related to peri-implant soft tissue overgrowth/hyperplasia and the possible need for soft tissue debulking/modification and mucosal/soft tissue graft around implants, which occurred commonly in combined bone and soft tissue grafts. These finding, however, are limited to low-level evidence in the form of a small number of retrospective observational studies.

\section{Limitations}

This systematic review has identified that the quality of evidence to inform clinical decision making regarding the use of implants in transported bone in this patient group is currently deficient. All studies included in the review were retrospective observational studies and in general reported on low patient and implant number and found to be at moderate to serious risk of bias.

A lack of consistency in definitions of the primary (implant related) outcome measures was observed. The outcome measures used in the studies varied and implant survival/success was not necessarily the primary outcome measure. Only 14 of the 20 studies reported the primary outcome measure to be implant survival/success whilst the remainder reported free flap survival, graft success and bone resorption of bone grafts as the primary outcome.

A clear deficiency of many of the studies was the imprecise and inconsistent definitions of implant survival or implant success, as detailed in Table 1. In addition, in a number of studies, the terminology 'implant success' and 'implant survival' were used interchangeably within the narrative making comparison of the studies challenging and rendering statistical analysis of the survival data inappropriate.

The reporting of implant survival data varied between studies and was presented in a variety of ways which included cumulative survival and implant survival incidence. In some cases, no attempt to estimate survival was made but adequate data was documented to enable its calculation (Table 2). Best practice would be the reporting of cumulative survival to give context to survival (time) and account for patient drop-out which may be high in this particular patient group. Due to the variability in the methods of data reporting and their comprehensiveness, there was insufficient confidence in extracted data to report statistical findings. Notably, as all studies presented different deficiencies in data reporting or study definitions, there was no clear way to further exclude studies using these criteria. 
As such, there is a clear need for a consensus on what minimum data set is required for published articles reporting on implant survival in this patient cohort to allow further investigation via systematic reviews (e.g., effect of benign vs malignant $\mathrm{H} \& \mathrm{~N}$ cancer and implant survival). The inclusion and exclusion criteria were highly variable, and in some studies, the criteria were such that there was a pre-disposition to selection bias and reporting higher implant survival rates. Patient follow-up was variable and also variably reported but in general was insufficient. Where possible, follow-up of at least 5 years is required to begin to evaluate the outcome of dental implant treatment. Unfortunately, information on long-term dental survival in this cohort is still scarce and the results of the present review should not be extrapolated beyond early implant survival.

\section{Conclusion}

Within the limitations of the current review, it can be concluded that implant survival in autogenous bone grafts in $\mathrm{H} \& \mathrm{~N}$ oncology patients appears to be promising with implant survival being reported at over $80 \%$ in 16 of the 20 studies included with 11 of these reporting implant survival of over $90 \%$ in follow-up ranging from 3 months [28] to 15 years [5]. However, there is a lack of good quality evidence in the way of prospective studies and randomised control trials. A lack of long-term survival studies with sufficient implant and patient numbers was identified, and therefore, the results of the present review should not be extrapolated to longer follow-up times. Prognostic factors affecting implant survival in autogenous bone grafts were also reviewed with higher implant failure in autogenous bone grafts being reported in implants placed into irradiated autogenous bone grafts. Weak evidence suggesting implant failure was higher in non-vascularised in comparison with vascularised autogenous bone grafts and that implant failure was greater in primary placed implants in vascularised bone grafts in this cohort was identified. Implant success was lower than implant survival and was most commonly related to peri-implant disease and an inability to prosthetically to restore the implant. This was predominantly related to unfavourable peri-implant soft tissue which is frequently found around implants placed into combined bone and soft tissue flaps.

In order to understand the use of implants in autogenous bone grafts in H\&N oncology patients larger, welldesigned prospective studies are required. There needs to be clear set definitions of implant survival and success and appropriate presentation and statistical analysis of the data so that studies can be brought together to enable meta-analysis.

\section{Abbreviations}

H\&N: Head and neck; MINORS: Methodological Index for Non-Randomized Studies; PRISMA: Preferred reporting items for systematic reviews and meta-analyses; QoL: Quality of life

\section{Availability of data and materials}

The dataset supporting the conclusions of this article and the statistical methods are included within the article.

\section{Authors' contributions}

All authors have made substantial contributions to the conception, design, acquisition of data and analysis and interpretation of data. All authors have been involved in drafting the manuscript and revising it. All authors approve this manuscript and agree to be accountable for all aspects of the work in ensuring that questions related to the accuracy or integrity of any part of the work are appropriately investigated and resolved.

Ethics approval and consent to participate

Not applicable.

Competing interests

Dominic P Laverty, Robert Kelly and Owen Addison declare that they have no competing interests.

\section{Publisher's Note}

Springer Nature remains neutral with regard to jurisdictional claims in published maps and institutional affiliations.

\section{Author details}

${ }^{1}$ Birmingham Community Healthcare NHS Foundation Trust, Birmingham B5 7EG, UK. 'University of Birmingham School of Dentistry, 5 Mill Pool Way, Birmingham B5 7EG, UK. ${ }^{3}$ School of Dentistry, University of Alberta, Edmonton, AB T6G 1C9, Canada.

Received: 16 January 2018 Accepted: 23 April 2018

Published online: 04 July 2018

References

1. Schoen PJ, Reintsema H, Raghoebar GM, Vissink A, Roodenburg JLN. The use of implant retained mandibular prostheses in the oral rehabilitation of head and neck cancer patients. A review and rationale for treatment planning. Oral Oncol. 2004;40:862-71.

2. Müller F, Schädler M, Wahlmann U, Newton JP. The use of implantsupported prostheses in the functional and psychosocial rehabilitation of tumor patients. Int J Prosthodont. 2004;17(5):512-7.

3. Reintsema H, van RP O, Schoen P, Raghoebar GM. Implant reconstructive prostheses in the mandible after ablative surgery: a rationale for treatment planning. J Fac Som Prost. 1998:4:129-40.

4. Chan MF, Hayter JP, Cawood JI, Howell RA. Oral rehabilitation with implantretained prostheses following ablative surgery and reconstruction with free flaps. Int J Oral Maxillofac Impl. 1997;12:820-7.

5. Marx RE, Morales MJ. The use of implants in the reconstruction of oral cancer patients. Dent Clin N Am. 1998:42:117-202.

6. David M. Cognetti, Randal S. Weber, Stephen Y. Lai, Head and neck cancer. Cancer. 2008;113(S7):1911-32.

7. Barrowman RA, Wilson PR, Wiesenfeld D. Oral rehabilitation with dental implants after cancer treatment. Aust Dent J. 2011;56(2):160-5.

8. Harrison SJ, Stratemann S, Redding WS. Dental implants for patients who have had radiation treatment for head and neck cancer. Spec Care Dentist. 2003;23:223-9

9. Esposito M, Grusovin MG, Felice P, Karatzopoulos G, Worthington HV, Coulthard $P$. Interventions for replacing missing teeth: horizontal and vertical bone augmentation techniques for dental implant treatment. Cochrane Database Syst Rev. 2009;7(4):CD003607.

10. Lekholm U, Wannfors K, Isaksson S, Adielsson B. Oral implants in combination with bone grafts. A 3-year retrospective multicenter study using the Brånemark implant system. Int J Oral Maxillofac Surg. 1999;28(3):181-7.

11. Schliephake $H$, Schmelzeisen $R$, Husstedt $H$, Schmidt-Wondera LU. Comparison of the late results of mandibular reconstruction using nonvascularized or vascularized grafts and dental implants. J Oral Maxillofac Surg. 1999;57(8):944-50, discussion 950-1. 
12. Moher D, Liberati A, Tetzlaff J, Altman DG. Preferred reporting items for systematic reviews and meta-analyses: the PRISMA statement. Ann Intern Med. 2009;15:264-9.

13. Moher D, Liberati A, Tetzlaff J, Altman DG. Preferred reporting items for systematic reviews and meta-analyses: the PRISMA statement. Public Libr Sci Med. 2002;6:e1000097.

14. Slim K, Nini E, Forestier D, Kwiatkowski F, Panis Y, Chipponi J. Methodological index for non-randomized studies (minors): development and validation of a new instrument. ANZ J Surg. 2003;73(9):712-6.

15. Schultes G, Gaggl A, Kärcher H. Stability of dental implants in microvascular osseous transplants. Plast Reconstr Surg. 2002;109(3):916-21; discussion 922-4

16. Yerit KC, Posch M, Seemann M. Implant survival in mandibles of irradiated oral cancer patients. Clin Oral Impl Res. 2006;17:337-44.

17. Linsen SS, Martini M, Stark H. Long-term results of endosteal implants following radical oral cancer surgery with and without adjuvant radiation therapy. Clin Implant Dent Relat Res. 2012;14(2):250-8.

18. Chiapasco M, Biglioli F, Autelitano L, Romeo E, Brusati R. Clinical outcome of dental implants placed in fibula free flaps used for the reconstruction of maxillomandibular defects following ablation for tumors or osteoradionecrosis. Clin Oral Impl Res. 2006;17:220-8.

19. Fenlon MR, Lyons A, Farrell S, Bavisha K, Banerjee A, Palmer RM. Factors affecting survival and usefulness of implants placed in vascularized free composite grafts used in post-head and neck cancer reconstruction. Clin Implant Dent Relat Res. 2012;14(2):266-72.

20. Ch'ng S, Skoracki RJ, Selber JC, et al. Osseointegrated implant based dental rehabilitation in head and neck reconstruction patients. Head Neck. 2016;38:E321-7.

21. Wang F, Huang W, Zhang C, Sun J, Kaigler D, Wu Y. Comparative analysis of dental implant treatment outcomes following mandibular reconstruction with double-barrel fibula bone grafting or vertical distraction osteogenesis fibula: a retrospective study. Clin Oral Implants Res. 2015;26(2):157-65.

22. Zou D, Huang W, Wang F, et al. Autologous ilium grafts: long-term results on immediate or staged functional rehabilitation of mandibular segmental defects using dental implants after tumor resection. Clin Implant Dent Relat Res. 2015;17(4):779-89.

23. Chiapasco M, Colletti G, Romeo E, Zaniboni M, Brusati R. Long-term results of mandibular reconstruction with autogenous bone grafts and oral implants after tumor resection. Clin Oral Impl Res. 2008:19:1074-80.

24. Buddula A, Assad DA, Salinas TJ, Garces YI, Volz JE, Weaver AL. Survival of dental implants in irradiated head and neck cancer patients: a retrospective analysis. Clin Implant Dent Relat Res. 2012;14(5):716-22.

25. Fierz J, Hallermann W, Mericske-Stern R. Patients with oral tumours. Part 1 prosthetic rehabilitation following tumour resection. Schweiz Monatsschr Zahnmed. 2013;123(2):91-105.

26. Teoh KH, Huryn JM, Patel S, et al. Implant prosthodontic rehabilitation of fibula free-flap reconstructed mandibles: a Memorial Sloan-Kettering Cancer Center review of prognostic factors and implant outcomes. Int J Oral Maxillofac Implants. 2005;20(5):738-46.

27. Burgess M, Leung M, Chellapah A, Clark JR, Batstone MD. Osseointegrated implants into a variety of composite free flaps: a comparative analysis. Head Neck. 2017;39(3):443-7.

28. Hessling SA, Wehrhan F, Schmitt CM, Weber M, Schlittenbauer T, Scheer M. Implant-based rehabilitation in oncology patients can be performed with high long-term success. J Oral Maxillofac Surg. 2015;73(5):889-96.

29. Watzinger F, Ewers R, Henninger A, Sudasch G, Babka A, Woelf G. Endosteal implants in the irradiated lower jaw. J Craniomaxillofac Surg. 1996;24(4):237-44.

30. Wu YQ, Huang W, Zhang ZY, Zhang ZY, Zhang CP, Sun J. Clinical outcome of dental implants placed in fibula-free flaps for orofacial reconstruction. Chin Med J. 2008;121(19):1861-5.

31. Shaw RJ, Sutton AF, Cawood Jl, et al. Oral rehabilitation after treatment for head and neck malignancy. Head Neck. 2005;27(6):459-70.

32. Klein MO, Grötz KA, Walter C, Wegener J, Wagner W, Al-Nawas B. Functional rehabilitation of mandibular continuity defects using autologous bone and dental implants - prognostic value of bone origin, radiation therapy and implant dimensions. Eur Surg Res. 2009;43(3):269-75.

33. Chiapasco M, Abati S, Ramundo G, Rossi A, Romeo E, Vogel G. Behavior of implants in bone grafts or free flaps after tumor resection. Clin Oral Impl Res. 2000;11:66-75.

34. Chambrone L, Mandia J Jr, Shibli JA, Romito GA, Abrahao M. Dental implants installed in irradiated jaws: a systematic review. J Dent Res. 2013; 92(12 Suppl):119S-30S.

\section{Submit your manuscript to a SpringerOpen ${ }^{\circ}$ journal and benefit from:}

- Convenient online submission

- Rigorous peer review

- Open access: articles freely available online

- High visibility within the field

- Retaining the copyright to your article

Submit your next manuscript at $\boldsymbol{\nabla}$ springeropen.com 